\title{
Correlation between Second to Fourth Digit Ratio and Anthropometric Variables Indicative of Cardiovascular Disease
}

\author{
Shveta Swami ${ }^{1,2}$ Virender Buddhiraja ${ }^{1,2}$ Rimpi Gupta ${ }^{1,2}$ Swati Bansal ${ }^{1,2}$ Neha Gaur ${ }^{1,2}$ \\ Deepak Sharma ${ }^{3}$ \\ ${ }^{1}$ Department of Anatomy, Kalpana Chawla Government Medical \\ College, Karnal, Haryana, India \\ 2 Pt Bhagwat Dyal University of Health Sciences, Rohtak, India \\ ${ }^{3}$ Department of Pediatric and Preventive Dentistry, RP Welltar \\ Hospital, Karnal, Haryana, India \\ Address for correspondence Shveta Swami, Associate Professor, M.B. \\ B.S, M.S., Dept. of Anatomy, Kalpana Chawla Govt. Medical college, \\ Karnal,132001, Haryana, India \\ (e-mail: shveta_swami@rediffmail.com). \\ J Morphol Sci 2019;36:28-32.
}

\begin{abstract}
Keywords

- 2D:4D ratio

- coronary heart disease

- correlation

- waist-to-hip ratio

- neck circumference

Second to fourth digit ratio (2D:4D) is a sexually dimorphic biometric marker. Regarding indirect evidence, there have been several studies that link the waist-tohip ratio (WHR) with the $2 \mathrm{D}: 4 \mathrm{D}$ ratio. If the $2 \mathrm{D}: 4 \mathrm{D}$ ratio is associated with testosterone and estrogen levels, it may be correlated with a risk of myocardial infarction (MI). The aim of the present study is to find out the correlation between anthropometric risk factors for cardiovascular disease and the 2D:4D ratio in 250 young females of the state of Haryana in Northern India. The present study was conducted on 250 females of the Haryana population aged between 17 and 35 years old. A series of 8 anthropometric measurements was obtained from the participants: height, weight, 2D:4D ratio, body mass index (BMI), waist circumference (WC), hip circumference (HC), neck circumference (NC), and WHR. The data was collected, tabulated and subjected to statistical computation using SPSS Statistics for Windows, Version 13.0 (SPSS Inc., Chicago, IL, USA). Strong positive associations between the NC and the WHR confirm that both measures are indicative of body fat. Also, a positive correlation between the 2D:4D ratio and the WHR suggests that low androgen levels in women are associated with a greater risk of obesity. Moreover, this result, as well as the positive correlation between $2 \mathrm{D}: 4 \mathrm{D}$ ratios and $\mathrm{NC}$, suggest that the digit ratio is indicative for being overweight in women and suggest a predisposition toward cardiovascular disease - however, these correlations of body measurements with digit ratios are not significant.
\end{abstract}

\section{Introduction}

Second to fourth digit ratio (2D:4D) is a sexually dimorphic biometric marker. It is influenced by prenatal estrogen and testosterone levels. High prenatal levels of androgens (high testosterone/estrogen) determine lower values of 2D:4D, and vice-versa. The Hox $A$ and Hox $D$ genes are responsible for both gonadal and digital differentiation. ${ }^{1}$

Relative finger lengths are determined before birth at 13 weeks of gestation. ${ }^{2}$ The gender difference is present in

received

July 31,2018

accepted

January 9, 2019

published online

February 19, 2019 children, 2,3 and gender differences in the 2D:4D ratio are robust across several ethnic groups and races. ${ }^{4-6}$

Regarding indirect evidence, there have been several studies that link the waist-to-hip ratio (WHR) with the 2D:4D ratio. ${ }^{5,7}$ In female subjects, the WHR appears to be directly linked to health and fertility, since it has been shown to be an accurate predictor of risk for various diseases. ${ }^{8,9}$ In men, studies have shown that aging is accompanied by decreasing levels of testosterone, which in turn decrease
Copyright $\odot 2019$ by Thieme Revinter

Publicações Ltda, Rio de Janeiro, Brazil
License terms

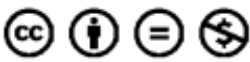


lean body mass and increase the deposition of abdominal fat. Testosterone supplementation in elderly male subjects and in healthy eugonadal men decreases the WHR and increases lean body mass. ${ }^{10,11}$ Manning et al found a negative relationship between the 2D:4D ratio and the age at the first myocardial infarction (MI), which means that men with a low 2D:4D ratio tended to have their first MI later in life than men with high 2D:4D ratios. ${ }^{12}$ Consequently, they suggested that the formation and maintenance of the cardiovascular system is sensitive to testosterone and estrogen in men, and that the $2 \mathrm{D}: 4 \mathrm{D}$ ratio is a marker for in utero and adult levels of these hormones. This has led to the assumption that if the 2D:4D ratio is associated with testosterone and estrogen levels, it may be correlated with a risk of MI. Manning et $\mathrm{al}^{12,13}$ found a negative relationship between the 2D:4D ratio and the age at the first MI, which means that men with a low 2D:4D ratio tended to have their first MI later in life than men with high 2D:4D ratios. ${ }^{12,13}$ Consequently, they suggested that the formation and maintenance of the cardiovascular system is sensitive to testosterone and estrogen in men, ${ }^{14}$ and that the $2 \mathrm{D}: 4 \mathrm{D}$ ratio is a marker for in utero and adult levels of these hormones.

Body obesity and metabolic syndrome, a cluster of conditions associated with an increased risk for type 2 diabetes and hypertension, are considered a major risk factor for coronary heart disease (CHD), associated with an elevated risk for stroke and early mortality. However, Ben-Noun et $\mathrm{al}^{15}$ tested a method of identifying overweight or obese patients solely by measuring their neck circumference (NC). Their results indicated a significant association between the NC and body mass index (BMI), age, weight, waist circumference (WC), hip circumference (HC), and WHR. A follow-up study also demonstrated that a higher NC is positively correlated with the factors of the metabolic syndrome and, therefore, it is likely to increase the risk of $\mathrm{CHD}{ }^{16}$

Finally, Fink et $\mathrm{al}^{17}$ studied the $2 \mathrm{D}: 4 \mathrm{D}$ ratio in relation to measurements of body shape and body fat distribution and found some support for an early organizational effect of sex hormones through the association between indices of female body shape, male BMI, and human finger length. ${ }^{17}$

White et $\mathrm{al}^{18}$ have shown the relationship between the 2D:4D ratio and elevated triglycerides, which supports the use of the $2 \mathrm{D}: 4 \mathrm{D}$ ratio as a non-invasive screening tool to assess the risk of metabolic syndrome.

The aim of the present study was to assess the correlation of the 2D:4D ratio with known risk factors for developing cardiovascular disease (CVD) in young females of the state of Haryana in Northern India. Because it is reflective of fetal androgen exposure, we have hypothesized that the 2D:4D ratio would correlate with parameters associated with CVD. If our hypothesis is correct, measuring the $2 \mathrm{D}: 4 \mathrm{D}$ ratio of a patient would be a non-invasive way to determine their risk of developing cardiovascular disease.

\section{Materials and Methodology}

The present study was conducted on 250 females of the state of Haryana in northern India, aged between 17 and 35 years old. Approval by the institutional ethical committee was obtained and the informed consent from all subjects was taken before conducting the study.

\section{Inclusion Criteria}

1. Young individuals between 18 and 35 years old.

2. Individuals of the state of Haryana.

3. Individuals with no morphologically identifiable physical anomalies or deformities.

\section{Exclusion Criteria}

1. Individuals who were not from the state of Haryana.

2. Pregnant females.

3. The subjects with any apparent physical hand anomalies, inflammation, trauma, or deformities, and those who had underwent a recent major surgery were excluded because of their unsuitability for the present investigation.

4. Subjects having any genetic, psychological, neurological or chronic diseases affecting the hand parameters.

5. Individuals with a history of any recent drug intake.

6. Females who were wheelchair bound or had difficulty in standing.

7. Diagnosed cases of heart disease, hypertension, diabetes mellitus, chronic diseases of major organs, and endocrine disorders.

8. Subjects $<18$ years old and $>35$ years old.

A series of eight anthropometric measurements were obtained with the participants:

1. Height

2. Body weight

3. $2 \mathrm{D}: 4 \mathrm{D}$ ratio

4. Body mass index

5. Waist circumference

6. Hip circumference

7. Neck circumference

8. Waist-to-hip ratio

9. Waist-to-height ratio (WHtR)

1. Height: Height was measured (to the nearest $0.5 \mathrm{~cm}$ ) with the subject standing in an erect position against a vertical scale of portable Seca 213 Portable stadiometer (Seca Deutschland,22089 Hamburg, Germany), with the head positioned so that the top of the external auditory meatus was in level with the inferior margin of the bony orbit. ${ }^{19}$

2. Body weight: Body weight was measured (to the nearest $0.5 \mathrm{~kg}$ ) with the subject standing motionless on a bathroom weighing Venus Electronic Bathroom scale (Ace incorporation, Jaipur, Rajasthan, India). ${ }^{19}$

3. 2D:4D ratio: It is defined as the ratio of the length of second digit (index finger) to the length of the fourth digit (ring finger). The measurement was taken from both hands with an electronic sliding Mitutoyo 6 AOC Digital Sliding Caliper (Mitutoyo, Japan) from the palmar side with the digits fully stretched and touching on a hard flat surface, with the second to fifth digits adducted and the thumb slightly extended. 
4. Body mass index: The BMI was calculated as weight in kilograms divided by the squared height in meters (weight in $\mathrm{kg} /$ height in $\left.\mathrm{m}^{2}\right)^{19}$

5. Waist circumference: The WC was measured by using bone landmarks as references with the help of a measuring tape. The World Health Organization (WHO) guidelines recommend the measurement of the WC at the midpoint between the lowest rib and the iliac crest (the highest point of the ilium). ${ }^{19}$

6. Hip Circumference: The HC was measured at the level of the greater trochanters with the help of a measuring tape. ${ }^{19}$ It is defined as the maximum circumference in the gluteal area.

7. Neck circumference: The NC $(\mathrm{cm})$ was measured at the level of the upper margin of the thyroid cartilage by using a measuring tape. ${ }^{20}$

8. Waist-to-hip ratio: The WHR was calculated using the following formula: WHR $=$ WC $(\mathrm{cm}) / \mathrm{HC}(\mathrm{cm})$

Each measurement was taken three times by the same individual, and the mean of the three measurements was considered as the final reading.

\section{Statistical analysis}

The data was collected, tabulated and statistically analyzed using SPSS Statistics for Windows, Version 13.0 (SPSS Inc., Chicago, IL, USA).. Descriptive statistics of each risk factor and pairwise correlations with the 2D:4D ratio were conducted. The descriptive statistics, means and standard deviations (SDs) of the body measurements and of the 2D:4D ratios are shown in - Table 1. The Pearson correlation ( $r$ ) was used for assessing the relationships between the $2 \mathrm{D}: 4 \mathrm{D}$ and the body measurements (-Table 2 ).

\section{Results}

Strong significant positive associations between NC and WHR confirm that both measures are indicative of body fat (-Table 3 ). The present findings of positive correlations

Table 1 Descriptive statistics, means and standard deviations of body measures and 2D:4D ratios

\begin{tabular}{|l|l|l|}
\hline Measurement & Mean & Standard deviation \\
\hline Height $(\mathrm{cm})$ & 145.85 & 7.85 \\
\hline Weight $(\mathrm{kg})$ & 37.95 & 12.67 \\
\hline WC & 67.93 & 7.85 \\
\hline HC & 85.62 & 8.57 \\
\hline NC & 28.60 & 2.70 \\
\hline BMI & 21.24 & 3.15 \\
\hline WHR & 0.72 & 0.20 \\
\hline RT 2D:4D & 0.98 & 0.03 \\
\hline LT 2D:4D & 0.97 & 0.01 \\
\hline
\end{tabular}

Abbreviations: BMI, body mass index; HC, hip circumference; LT 2D:4D, second to fourth digit ratio of left hand; NC, neck circumference; RT 2D:4D, second to fourth digit ratio of right hand; WC, waist circumference; WHR, waist-to-hip ratio.
Table 2 Correlation coefficients for the relationships between 2D:4D ratios and body measures

\begin{tabular}{|l|l|l|l|l|}
\hline & $\begin{array}{l}\text { Rt 2D:4D } \\
\text { ratio }\end{array}$ & $p$-value & $\begin{array}{l}\text { Lt 2D:4D } \\
\text { ratio }\end{array}$ & $p$-value \\
\hline Age & 0.034 & 0.66 & 0.044 & 0.57 \\
\hline Height & 0.126 & 0.066 & 0.034 & 0.63 \\
\hline Weight & 0.158 & 0.02 & 0.130 & 0.06 \\
\hline WC & -0.004 & 0.96 & 0.022 & 0.75 \\
\hline HC & 0.025 & 0.72 & -0.032 & 0.64 \\
\hline NC & 0.031 & 0.66 & 0.023 & 0.74 \\
\hline BMI & 0.034 & 0.66 & 0.044 & 0.57 \\
\hline WHR & 0.127 & 0.06 & 0.114 & 0.09 \\
\hline
\end{tabular}

Abbreviations: BMI, body mass index; HC, hip circumference; LT 2D:4D, second to fourth digit ratio of left hand; NC, neck circumference; RT 2D:4D, second to fourth digit ratio of right hand; WC, waist circumference; WHR, waist-to-hip ratio.

between 2D:4D ratios and NC (-Table 2 ) in women of the state of Haryana suggest a possible predisposition toward CHD. Neck circumference is also significantly positively correlated with weight, WC, and HC in the present study (-Table 3 ).

\section{Discussion}

No significant correlation between the 2D:4D ratio and the WHR for females was found in any of the studies shown in - Table 4. The WC and HC are negatively correlated with the 2D:4D ratio, but this correlation is significant only in the study of Fink et al. ${ }^{17}$ The WHR and the BMI were negatively correlated with the 2D:4D ratio in the studies by Fink et al ${ }^{17}$ and by Fink et al, ${ }^{20}$ but not in the present study.

Oyeyemi et $\mathrm{al}^{21}$ have shown a positive significant correlation between the 2D:4D ratio, BMI, and the WHtR, suggesting a possible predisposition toward cardiovascular disease. The authors have also shown a significant correlation between the $2 \mathrm{D}: 4 \mathrm{D}$ ratio and the $\mathrm{NC}$, but this positive correlation was not significant in the present study.

Oyeyemi et $\mathrm{al}^{22}$ have shown that digit ratios in both hands failed to show any significant correlations with the NC in female subjects. Metabolic syndrome markers (BMI, WC, NC) significantly correlate with both right and left 2D:4D ratios in males and females. Thus, the $2 \mathrm{D}: 4 \mathrm{D}$ ratio could be used as a surrogate marker for the risk of metabolic syndrome and CVD in Ilorin, Northcentral Nigeria.

Danborno et $\mathrm{al}^{23}$ showed a significant relationship between $2 \mathrm{D}$ and $4 \mathrm{D}$ lengths in the right and left hands with chest circumference, WC and HC only in males, but not in females, which is in line with the present study.

Manning ${ }^{4}$ has proven in his study that mothers with high WHR, which is associated with high testosterone and low estrogen, tend to have children with low 2D:4D ratios. Mothers with low 2D:4D ratios tend to have children with low 2D:4D ratios, and their children have high concentrations of testosterone in their amniotic fluid. 
Table 3 Pearson correlation coefficients of the body measures

\begin{tabular}{|l|l|l|l|l|l|l|l|}
\hline & Height & Weight & WC & HC & NC & BMI & WHR \\
\hline Height & 1 & 0.418 & 0.511 & 0.536 & 0.652 & -0.032 & 0.368 \\
\hline Weight & 0.418 & 1 & 0.376 & 0.311 & 0.373 & 0.046 & 0.250 \\
\hline WC & 0.511 & 0.376 & 1 & 0.800 & 0.795 & 0.300 & 0.720 \\
\hline HC & 0.536 & 0.311 & 0.800 & 1 & 0.698 & 0.268 & 0.563 \\
\hline NC & 0.652 & 0.373 & $0.795^{* *}$ & $0.698^{* *}$ & 1 & 0.060 & $0.770^{* *}$ \\
\hline BMI & -0.032 & 0.046 & 0.306 & 0.268 & 0.060 & 1 & 0.009 \\
\hline WHR & 0.368 & 0.250 & 0.720 & 0.563 & 0.770 & 0.009 & 1 \\
\hline
\end{tabular}

Abbreviations: BMI, body mass index; HC, hip circumference; NC, neck circumference; WC, waist circumference; WHR, waist-to-hip ratio.

${ }^{* *}$ Correlation is significant at 0.01 level

Table 4 Correlation between 2D:4D ratio and body measures in different studies

\begin{tabular}{|l|l|l|l|l|l|l|}
\hline & \multicolumn{2}{|l|}{ Fink et al (2003) $^{17}$} & \multicolumn{2}{l|}{ Fink et al (2006) $^{20}$} & \multicolumn{2}{l|}{ Present study } \\
\hline & Rt 2D:4D & Lt 2D:4D & Rt 2D:4D & Lt 2D:4D & Rt 2D:4D & Lt 2D:4D \\
\hline WC & -0.358 & -0.380 & -0.146 & -0.023 & -0.004 & -0.022 \\
\hline HC & -0.307 & -0.296 & -0.029 & -0.014 & 0.025 & -0.032 \\
\hline BMI & -0.193 & -0.130 & -0.006 & -0.070 & 0.034 & 0.044 \\
\hline WHR & -0.082 & -0.140 & -0.152 & -0.012 & 0.127 & 0.114 \\
\hline NC & - & - & -0.080 & -0.031 & 0.031 & 0.23 \\
\hline
\end{tabular}

Abbreviations: BMI, body mass index; HC, hip circumference; LT 2D:4D, second to fourth digit ratio of left hand; NC, neck circumference; RT 2D:4D, second to fourth digit ratio of right hand; WC, waist circumference; WHR, waist-to-hip ratio.

White et $\mathrm{a}^{18}$ have shown the relationship between the 2D:4D ratio and elevated triglycerides, but found no relationship between WC and the 2D:4D ratio of either hand, which is in line with the present study.

\section{Conclusions}

- There is a significant association between NC and height, weight, WC, HC and WHR. A higher NC is positively correlated with factors of metabolic syndrome and, therefore, is likely to increase the risk of CHD.

- The present findings of positive correlations between 2D:4D ratios and the NC in women of the state of Haryana suggest a possible predisposition toward cardiovascular disease, but the correlation is not significant.

- The present study did not show any significant correlation between the right and left 2D:4D ratios with WC, HC, BMI, NC, or WHR.

- Body mass index, WHR, and NC were positively correlated with the 2D:4D ratio, whereas WC and HC were negatively correlated with the $2 \mathrm{D}: 4 \mathrm{D}$ ratio, but the correlation was not significant.

The present study is not without limitations. The first limitation is its small sample size. A large sample would provide power to limit the potential for bias in predictive models. Variations in the study design and in the mode of measure- ment of the digits may introduce variability that could result in differing outcomes when reporting data. A further investigation is required on a larger number of subjects in order to obtain a more detailed picture of possible associations.

Conflicts of Interests

The authors have no conflicts of interests to declare.

\section{References}

1 Kanchan T, Kumar GP, Menezes RG. Index and ring finger ratio-a new sex determinant in south Indian population. Forensic Sci Int 2008;181(1-3):53.e1-53.e4

2 Garn SM, Burdi AR, Babler WJ, Stinson S. Early prenatal attainment of adult metacarpal-phalangeal rankings and proportions. Am J Phys Anthropol 1975;43(03):327-332

3 Manning JT, Wood S, Vang E, et al. Second to fourth digit ratio (2D:4D) and testosterone in men. Asian J Androl 2004;6(03): 211-215

4 Manning JT. Digit Ratio: A Pointer to Fertility, Behaviour and Health. New Jersey: Rutgers University Press; 2002

5 Manning JT, Barley L, Walton J, et al. The 2nd:4th digit ratio, sexual dimorphism, population differences, and reproductive success. evidence for sexually antagonistic genes? Evol Hum Behav 2000; 21(03):163-183

6 Peters M, Tan U, Kang Y, Teixeira L, Mandal M. Sex-specific fingerlength patterns linked to behavioral variables: consistency across various human populations. Percept Mot Skills 2002;94(01):171-181

7 Manning JT, Trivers RL, Singh D, Thornhill R. The mystery of female beauty. Nature 1999;399(6733):214-215, author reply 216 
8 Singh D. Ideal female body shape: role of body weight and waistto-hip ratio. Int J Eat Disord 1994;16(03):283-288

9 Abbott DH, Dumesic DA, Franks S. Developmental origin of polycystic ovary syndrome - a hypothesis. J Endocrinol 2002; 174(01):1-5

10 Rebuffé-Scrive M, Mårin P, Björntorp P. Effect of testosterone on abdominal adipose tissue in men. Int J Obes 1991;15(11):791-795

11 Vermeulen A, Goemaere S, Kaufman JM. Testosterone, body composition and aging. J Endocrinol Invest 1999;22(5, Suppl) 110-116

12 Manning JT, Bundred PE. The ratio of 2nd to 4th digit length and age at first myocardial infarction in men: a link with testosterone. Br J Cardiol 2001;8:720-723

13 Manning JT, Taylor R, Bundred PE. The ratio of 2nd and 4th digit length: a prenatal correlate of ability in sport. In: Reilly T, MarfellJones M (eds.) Kinanthropometry VIII. Routledge: London; 2003

14 English KM, Mandour O, Steeds RP, Diver MJ, Jones TH, Channer KS. Men with coronary artery disease have lower levels of androgens than men with normal coronary angiograms. Eur Heart J 2000;21(11):890-894

15 Ben-Noun L, Sohar E, Laor A. Neck circumference as a simple screening measure for identifying overweight and obese patients. Obes Res 2001;9(08):470-477

16 Ben-Noun L, Laor A. Relationship of neck circumference to cardiovascular risk factors. Obes Res 2003;11(02):226-231
17 Fink B, Neave N, Manning JT. Second to fourth digit ratio, body mass index, waist-to-hip ratio, and waist-to-chest ratio: their relationships in heterosexual men and women. Ann Hum Biol 2003;30(06):728-738

18 White M, Jarrett T, Komar C. Correlation between Digit length ratios \& risk factors associated with metabolic syndrome. J Metab Syndr 2017;6:221

19 Deshmukh PR, Gupta SS, Dongre AR, et al. Relationship of anthropometric indicators with blood pressure levels in rural Wardha. Indian J Med Res 2006;123(05):657-664

20 Fink B, Manning JT, Neave N. The 2nd-4th digit ratio (2D:4D) and neck circumference: implications for risk factors in coronary heart disease. Int J Obes 2006;30(04):711-714

21 Oyeyemi BF, Adebayo JO, Anifowoshe AT, Iyiola OA. Relationship between Ratio of Second and Fourth Digit and Obesity Traits among Different Ethnic Groups in Ilorin, North Central Nigeria. Not Sci Biol 2016;8(04):396-400

22 Oyeyemi BF, Iyiola OA, Oyeyemi AW, Oricha KA, Anifowoshe AT, Alamukii NA. Sexual dimorphism in ratio of second and fourth digits and its relationship with metabolic syndrome indices and cardiovascular risk factors. J Res Med Sci 2014;19(03):234-239

23 Danborno B, Adebisi SS, Adelaiye AB \& Ojo SA. Sexual Dimorphism and Relationship between Chest, Hip and Waist Circumference with 2D, 4D and 2D:4D in Nigerians. The Internet Journal of Biological Anthropology. 2008, Volume 1, Number 2 